\title{
Psychological and Cultural Factors in the Process of Occupational Achievement
}

\author{
OTIS DUDLEY DUNCAN \\ University of Michigan \\ and \\ DAVID L. FEATHERMAN \\ University of Wisconsin
}

\begin{abstract}
An eight-equation model embodies the hypothesis that cultural differences among ethnic-religious groups give rise to differences in psychological dispositions, which, though not directly observable, influence occupational achievement, directly or via educational attainment, while being subject to feedback from one or the other of these endogenous variables. Dispositions are reflected in three fallible indicators, constructed from items in a survey interview of native white men in the Detroit area; the survey also secured socioeconomic measures and an estimate of intelligence. The model is block recursive and over-identified. Parameter estimates are secured by a sequence of ordinary least squares and two-stage least squares procedures, after solving out the structural equations to eliminate the unobservable variables. Numerical results do not strongly support the "Protestant Ethic" theory of achievement, but do suggest that the influence of education on occupation is mediated by motivational as well as cognitive and institutional factors.
\end{abstract}

\section{THE PROBLEM}

Social and behavioral scientists have suggested that several distinct kinds of variables play important roles in the process of social stratification. But progress toward a comprehensive model of stratification, incorporating all of these variables, has been uneven. We do have rather firm estimates of the correlations between socioeconomic status of the family of orientation and adult achievement as measured by educational attainment, occupational level, and income (Blau and Duncan, 1967; Duncan, Featherman, and Duncan, 1968). Several bodies of relatively reliable data have documented differentials in achievement-not entirely attributable to concomitant variation in socioeconomic background-among ethnic and religious groups (Duncan and 
Duncan, 1968; Goldstein, 1969; Gockel, 1969; Warren, 1970). It is also rather well established that psychometric tests of ability correlate substantially with both socioeconomic background and educational attainment (Sewell and Shah, 1967). The specific contribution of ability to occupational achievement is, however, somewhat difficult to estimate (Duncan, 1968). Even more uncertain is our knowledge about the social psychological variables identified variously as motives, aspirations, value orientations, and so forth (Kahl, 1965; Stacey, 1965; Crockett, 1966). Efforts to include such variables in models of the achievement process (e.g., Duncan, 1969) have served to highlight the difficult problems of measurement and inference that are encountered as soon as one attempts to achieve any degree of rigor in this area.

One problem has been the difficulty in assembling for a single representative sample a set of measurements on each of the variables mentioned. Kahl (1965, p. 678), for example, had occasion to remark, "I am still waiting for a study that combines both intelligence and motivation within the context of social structure." Rosen (1959) produced evidence of differences among ethnic and religious groups in achievement orientations, but we must turn to other bodies of data, such as those cited above, for evidence of actual differences in achievement. Comparability between such different bodies of data is always in question. Lenski (1963) was in a somewhat more favorable position; he was able to put together information from one cross-section sample on socio-religious group membership, socioeconomic origins, occupational achievement, and attitudes and values concerning work. He did not, however, make use of a well-specified model of socioeconomic achievement; nor did he attempt to cope explicitly with the problem of reciprocal causation as between his psychological variables and his measure of achievement. Despite these deficiencies, Lenski's research poses our problem in an especially clear way. Moreover, the attempt to replicate aspects of Lenski's study (Schuman, 1971) led to the creation of the body of data we shall employ here.

The most nearly satisfactory research design developed thus far appears in Featherman's (1971) investigation of social and psychological explanations of religio-ethnic subgroup differences in achievement. A particular advantage of his study was the availability of panel data, including three indexes of motivational orientations measured at an early stage of the socioeconomic career along the subsequent measures of achievement 6-10 years later. The study provided, at best, modest support for the notion that motives and other personality dimensions function as "key" (Crockett, 1966) intervening variables in the process of achievement.

No doubt it is premature to draw any firm conclusions in this area. A critic might easily find fault with the particular indexes of achievement orientation that Featherman had available; his study included no estimate of the respondent's intellectual ability; and one might wish to entertain models 
specified somewhat differently from his. The present study likewise must be seen as yet another effort to wrest some intelligence from less than ideal information and to cope with intrinsically refractory problems of conceptualization and model specification.

We have data from Project 938 of the Detroit Area Study (DAS). This involved a cross-sectional sample of native white men 21-64 years old, living in metropolitan Detroit in 1966 . The responsc rate of $80 \%$ produced 985 interviews, of which 28 were double weighted to take account of subsampling introduced in the final stage of the field work (Schuman, 1971). Of the 1013 weighted cases, 887 are available for the present analysis, since they provide information on all the variables investigated here. (See Tables 1 and 2 for list of variables.)

Using these variables (described in detail in section 2), we propose (in section 3) a model in which cultural differences among ethnic and religious groups give rise to differences in psychological dispositions; while the latter, in turn, influence occupational achievement, whether directly or via educational attainment. We consider (in section 4) some alternative specifications of the model, selecting one as most relevant for the purpose at hand. Estimates obtained on this specification are presented and discussed in terms of the light they may shed on the problem of assessing the role of psychological factors in the process of achievement.

\section{DESCRIPTION OF VARIABLES}

In the DAS data we have measures of family background (father's occupation and education) and socioeconomic achievement (respondent's education and occupation) much like those used in other work on occupational achievement (Duncan, Featherman, and Duncan, 1968). Indeed, special pains were taken to ensure that the coding of the occupation items followed the procedures used by the Bureau of the Census, so that rather strict comparability to the occupational data in the study of Blau and Duncan (1967) can be assumed. The DAS data also include a measure of intelligence, the respondent's score on the 13-item Similarities Subscale of the Wechsler Adult Intelligence Scale. Wechsler (1955, pp. 13-17) reports an odd-even reliability of .85 for this subscale and indicates that it correlates about .80 with the full scale score (based on eleven subtests, including Similarities). We would have preferred to have a more comprehensive intelligence test score obtained around age 12 , i.e., at a point in the life cycle clearly prior to the completion of schooling and entry into an occupational career. This information is not available, and we have merely adopted the expedient of treating the WAIS Similarities score, as obtained, as if it were such a measure. No doubt we thereby incur error, although it is not clear that measurement error with 
TABLE 1

Correlation Matrix for Selected Variables in DAS Data for Native White Men Living in Detroit Metropolitan Area: $1966^{a}$

\begin{tabular}{|c|c|c|c|c|c|c|c|c|c|c|c|c|c|}
\hline \multirow[b]{2}{*}{ Variable $b$} & \multicolumn{11}{|c|}{ Variable $b^{*}$} & \multirow[b]{2}{*}{ Mean } & \multirow[b]{2}{*}{ S.D. } \\
\hline & $y_{1}$ & $y_{2}$ & $y_{3}$ & $y_{4}$ & $y_{5}$ & $y_{f}$ & $y_{g}$ & $y_{h}$ & $x_{6}$ & $x_{7}$ & $x_{8}$ & & \\
\hline $\begin{array}{l}\text { Prot. } \\
\text { Ethic } y_{1}\end{array}$ & & .098 & .196 & .252 & .242 & .338 & .219 & .262 & .232 & .134 & .184 & 0.460 & 0.397 \\
\hline $\begin{array}{l}\text { Occ. } \\
\text { Asp. } \quad y_{2}\end{array}$ & & & .302 & .329 & .363 & .306 & .386 & .366 & .249 & .163 & .143 & 46.9 & 19.0 \\
\hline $\begin{array}{l}\text { Soc. } \\
\text { Class } y_{3}\end{array}$ & & & & .467 & .445 & .414 & .401 & .540 & .309 & .258 & .242 & 3.45 & 1.15 \\
\hline $\begin{array}{l}\text { R's } \\
\text { Occ. } y_{4}\end{array}$ & & & & & .601 & .746 & .548 & .864 & .431 & .303 & .286 & 45.9 & 24.2 \\
\hline R's & & & & & & & & & & & & & \\
\hline $\begin{array}{r}\text { Educ. } y_{s} \\
y_{f} \\
y_{g} \\
y_{h}\end{array}$ & & & & & $\ldots$ & $\begin{array}{l}.625 \\
\ldots\end{array}$ & $\begin{array}{l}.893 \\
.565 \\
\ldots\end{array}$ & $\begin{array}{l}.825 \\
.736 \\
.743 \\
. .\end{array}$ & $\begin{array}{l}.569 \\
.687 \\
.499 \\
.544\end{array}$ & $\begin{array}{l}.336 \\
.399 \\
.297 \\
.478\end{array}$ & $\begin{array}{l}.337 \\
.545 \\
.294 \\
.387\end{array}$ & $\begin{array}{c}5.07 \\
\ldots \\
\ldots \\
\ldots\end{array}$ & $\begin{array}{l}1.58 \\
0.13 \\
5.58 \\
0.62\end{array}$ \\
\hline $\begin{array}{l}\text { Intelli- } \\
\text { gence } x_{6}\end{array}$ & & & & & & & & & $\ldots$ & .278 & .262 & 14.0 & 5.3 \\
\hline $\begin{array}{l}\text { Fa's } \\
\text { Occ. } \quad x_{7}\end{array}$ & & & & & & & & & & $\cdots$ & .469 & 34.0 & 23.6 \\
\hline $\begin{array}{l}\text { Fa's } \\
\text { Educ. } x_{8}\end{array}$ & & & & & & & & & & & & 3.36 & 1.80 \\
\hline
\end{tabular}

$a_{\text {Based on }} 887$ men reporting all variables.

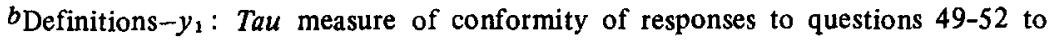
order implied by "Protestant" orientation to work; $y_{2}$ : Occupational aspiration scale; $y_{3}$ : Subjective social class identification; $y_{4}$ : Respondent's current (1966) occupation scored on Duncan socioeconomic index; $y_{5}$ : Years of school completed by respondent, transformed scale, with score of 2 for $0-8$ grades, 4 for $9-11$ grades, 5 for 12 grades, 6 for some college, 7 for college graduate, 8 for one or more years of graduate training; $y_{f}$, $y_{g}, y_{h}$ : Unmeasured variables (see text). Variables $\hat{y}_{f}, \hat{y}_{g}$, and $\hat{y}_{h}$ were estimated for each respondent, using the regression coefficients in Table 3 ; the correlations reported here were computed directly from these estimated scores; $x_{6}$ : Score on Similarities subtest of Wechsler test of adult intelligence; $x_{7}$ : Father's occupation, scored on Duncan socioeconomic index; and $x_{8}$ : Years of school completed by father, transformed scale as in variable $y_{5}$.

respect to this variable is more serious than it is with respect to father's occupation or education. In any event, it has been shown (Duncan, Featherman, and Duncan, 1968, section 6.5) that the expedient followed here produces estimates very similar to those yielded by a much more elaborate and (presumably) better justified procedure used with another set of data (Duncan, 1968).

Despite the modest sample size, we have used a fairly elaborate composite classification of religious preferences and ethnic group affiliations. 
TABLE 2

Mean Scores on Measured Variables by Religion-Ethnic Categories, for Sample of 887 Men in 1966 DAS Sample Reporting All Variables $a$

\begin{tabular}{|c|c|c|c|c|c|c|c|c|c|c|}
\hline \multirow[b]{2}{*}{$j$} & \multirow[b]{2}{*}{ Religion-Ethnic Category } & \multirow[b]{2}{*}{$n_{j}$} & \multicolumn{8}{|c|}{ Variable $b$} \\
\hline & & & $y_{1}$ & $y_{2}$ & $y_{3}$ & $y_{4}$ & $y_{s}$ & $x_{6}$ & $x_{\eta}$ & $x_{8}$ \\
\hline 1 & Jewish & 21 & .045 & 10.3 & 1.03 & 19.1 & 1.60 & 2.5 & 21.2 & .93 \\
\hline 2 & Irish Catholic & 60 & -.046 & -0.5 & .20 & 4.3 & .28 & 1.1 & 6.7 & .49 \\
\hline 3 & German Catholic & 68 & .046 & 0.8 & -.20 & 1.2 & .14 & 0.6 & 2.2 & .33 \\
\hline 4 & French Catholic & 49 & -.072 & -3.6 & -.25 & -3.3 & -.03 & 0.0 & -0.3 & -.15 \\
\hline 5 & Polish Catholic & 93 & -.036 & -3.3 & -.21 & -0.3 & -.36 & -1.4 & -9.3 & -.52 \\
\hline 6 & Italian Catholic & 36 & -.110 & 3.6 & -.09 & 2.3 & .16 & 0.0 & -5.6 & .03 \\
\hline 7 & Catholic, other N.W. Europe & & & & & & & & & \\
\hline & and North America & 32 & .034 & -0.3 & -.04 & -4.7 & -.50 & -1.6 & 5.1 & .52 \\
\hline 8 & Other Catholic and & & & & & & & & & \\
\hline & Orthodox & 54 & -.004 & 0.8 & -.12 & 0.3 & .01 & -0.5 & -5.5 & -.41 \\
\hline 9 & German Lutheran & 49 & .059 & 1.7 & .16 & 5.1 & .22 & 0.8 & -2.3 & -.11 \\
\hline 10 & Other Lutheran & 48 & -.047 & -6.1 & .11 & -7.7 & -.23 & -1.1 & -1.2 & .04 \\
\hline 11 & Presbyterian & 72 & .104 & 2.5 & .22 & 10.0 & .75 & 1.9 & 11.3 & .39 \\
\hline 12 & Episcopalian & 31 & .089 & 2.5 & .71 & 10.5 & .68 & 2.8 & 18.5 & 1.55 \\
\hline 13 & Methodist & 71 & .098 & 1.4 & .11 & 0.3 & .02 & 1.0 & 0.4 & -.19 \\
\hline 14 & Baptist & 91 & -.090 & 0.4 & -.41 & -9.2 & -.69 & -2.2 & -9.2 & -.41 \\
\hline 15 & Protestant, nondenomi- & & & & & & & & & \\
\hline & national & 32 & -.078 & -5.8 & -.07 & -0.9 & -.72 & -0.2 & -4.0 & -.23 \\
\hline 16 & "Fundamentalist" groups & 26 & .064 & -7.0 & -.80 & -17.9 & -.91 & -3.5 & -15.6 & -.70 \\
\hline 17 & No religion & 28 & -.060 & -0.5 & .23 & 4.3 & -.07 & 0.5 & 1.2 & -.50 \\
\hline 18 & Residual & 26 & .056 & 10.7 & .67 & 11.9 & .78 & 2.0 & 12.1 & .26 \\
\hline & relation ratio & $\ldots$ & .177 & .198 & .294 & .307 & .328 & .285 & .357 & .271 \\
\hline
\end{tabular}

$a_{\text {Deviations from grand means, Table } 1 .}$

$b$ See Table 1 for full identification. $y_{1}$ : Protestant Ethic; $y_{2}$ : Occupational Aspiration; $y_{3}$ : Social Class Identification; $y_{4}$ : Respondent's occupation; $y_{5}$ Respondent's education; $x_{6}$ : Intelligence; $x_{7}:$ Father's occupation; and $x_{8}$ : Father's education.

Jewish respondents, irrespective of national origins, are treated as a single category. Five main nationalities are distinguished among Catholics, and two additional categories account for the remainder of the Catholics. German Lutherans are distinguished from other Lutherans. For the remaining religious groups, nationality is ignored. In point of fact, heavy majorities in the several major Protestant denominations report northwest European origins. We distinguish four such denominations in addition to the Lutherans. Nondenominational "Protestants," members of any of the several "Fundamentalist" groups, and respondents having no religious preference account for three more categories. The residual consists of a miscellany of other religions, and other denominations, the largest single one being Congregational. Altogether, then, we have 18 categories (listed in Table 2) in our religion-ethnic classification. They are represented by as few as 21 respondents (Jewish) or as many as 93 
(Polish Catholic). Naturally, mean scores on socioeconomic and attitude variables estimated for such small samples are subject to a good deal of sampling error, so that we are well advised to avoid the temptation to interpret differences between specific denominational or ethnic groups. Moreover, we do not assume that there are in the population substantial differences in socioeconomic background or achievement for all such pairs of groups. The reason for retaining this much detail in the classification, therefore, is simply to allow the religion-ethnic variable to produce as much variation as it can. If we must err, we prefer in the present context to err on the side of overrather than underestimating this variation. In this connection, we have been influenced by Warren's (1970) argument that "Protestant" is not a socioeconomically homogeneous category and by the growing appreciation that significant ethnic differentiation persists among Catholics, even in the "triple melting pot" (Lenski, 1963, p. 362).

Three items in the DAS questionnaire were selected as indicators of psychological dispositions (motives or orientations): (1) a measure of the degree to which the respondent's work values conform to the "Protestant Ethic"; (2) a measure of occupational aspiration; and (3) the respondent's subjective social class identification. Some description and comments on these are in order.

The measure of "Protestant" work values was adapted from the research of Lenski (1963). Our score was derived from responses to this series of questions:

Q.49. Now I'd like to ask you some more questions about your own interests and ideas. Would you please look as this card, and tell me which thing on this list you would most prefer in a job.

1. High income

2. No danger of being fired

3. Short working hours, lots of free time

4. Chances for improvement

5. The work is important and gives a feeling of accomplishment

Q. 50. Which comes next?

Q. 51. Which is third most important?

Q. 52. Which is least important?

The wording of the alternatives is the same as that used by Lenski, except that in the fourth alternative the word "improvement" was used where Lenski's question read "advancement." Note that the series of questions has the effect of requiring the respondent to make a complete ranking of the five alternatives. To use all the information in this ranking, we need some assumptions about the relationship of the alternatives to the "Protestant" norm. We followed Lenski's (1963, p. 89) interpretation of the meaning of the alternatives: 
Each of these, we believed, represented a separate and distinct basis for evaluating jobs and careers. The last alternative is closest to the Protestant Ethic as conceived by Weber; it stresses both the worth of the work and the personal satisfactions it can afford. The first alternative, in contrast, stresses only the extrinsic satisfactions linked with work-the paycheck. In much of the current literature on the Protestant Ethic, this, together with a desire for advancement, is conceived to be the essence of the Protestant Ethic. While it is undoubtedly futile at this late date to try to "purify" sociological usage, it may at least prove worthwhile to call attention to these two divergent conceptions of the Protestant Ethic. Of our five alternatives, the fifth best expresses the classical Weberian understanding of the term, the first the current popular understanding, while the fourth occupies the middle ground between them. A concern for chances for advancement is consistent with both the classical and current usages.

The third alternative on our list was designed to express a view completely in opposition to any conception of the Protestant Ethic. The second was designed with the same purpose, but in retrospect it seems somewhat less in conflict with the Weberian definition than it seemed at first, since it does express a desire to work.

On the basis of this discussion, we placed the five alternatives in Q. 49 in the following rank order according to the degree to which they approach the "Protestant" norm of a structure of work values: $5-4-1-2-3$, in which the first choice is alternative No. 5 and the last choice No. 3. A respondent who placed the alternatives in just this order would be considered to conform perfectly to the Protestant Ethic in terms of his work values.

To score the responses to this series of questions we constructed for each respondent the implicit rank order of the five alternatives. We then computed Kendall's tau-statistic between the respondent's rank order and the standard or normative order. A value of tau of +1.0 represents perfect agreement of the respondent with the "Protestant" norm, while a value of -1.0 represents a perfect disagreement. The following distribution of respondents according to values of tau was obtained:

\begin{tabular}{|c|c|}
\hline tau & $f$ \\
\hline 1.0 & 102 \\
\hline 0.8 & 220 \\
\hline 0.6 & 208 \\
\hline 0.4 & 199 \\
\hline 0.2 & 119 \\
\hline 0.0 & 68 \\
\hline-0.2 & 38 \\
\hline-0.4 & 21 \\
\hline-0.6 & 15 \\
\hline-0.8 & 10 \\
\hline-1.0 & 2 \\
\hline NA & 11 \\
\hline
\end{tabular}

Total 
As Lenski notes, there is a high degree of endorsement of the Protestant Ethic in the general population. Only a small minority of men present a ranking that leats to a negative value of tau. In using the value of tau as a measure of the degree to which the respondent's orientation conforms to the Protestant Ethic, therefore, we are producing something like Allport's (1934) J-curve of conformity to a social norm, although conformity is here measured in ideological rather than behavioral terms.

The second indicator is a variable that purports to measure the respondent's achievement orientation to occupations. It is based on responses to this question:

Q. 56. Now suppose you were starting out in life and had to choose a job (occupation) for the first time. Would you look at this list please and tell me whether you would be satisfied or dissatisfied about the prospect (idea) of entering each of these lines of work?

\begin{tabular}{lcc} 
& Satisfied & Dissatisfied \\
\cline { 2 - 2 } a. Clerk in a store & - & - \\
b. Carpenter & - & - \\
c. Lawyer & - & - \\
d. Bookkeeper & - & - \\
e. Construction laborer & - & - \\
f. Public school teacher & - & - \\
g. Truck driver & - & - \\
h. Garage mechanic & - & -
\end{tabular}

A rationale for interpretation of data derived in this way has been offered by Morgan and others (1962, Appendix C). They suggest that the need for achievement is a "supposedly enduring personality trait-a disposition to strive for success." From the literature on achievement motivation, Morgan and his collaborators deduced that

An index of achievement motivation should ... be provided by the extent to which an individual places high values on succeeding in the difficult, high prestige occupations, and low values on succeeding in the easy occupations.

These investigators used a procedure resembling the one employed here; however, there are differences in the list of occupations, the phrasing of the question, and the scoring of the responses.

Our procedure was to assign to each of the eight occupations in Q. 56 its score on Duncan's socioeconomic index (Reiss and others, 1961). Then, for each respondent, we took the mean score of those occupations that he deemed satisfactory to be his score on an occupational aspiration scale. This method of scoring resembles that used for attitude scales constructed by Thurstone's method of equal-appearing intervals (Schuessler, 1971, p. 320). In our DAS sample, the occupational aspiration score has a mean of 46.9 and a standard deviation of 19.0. As Table 1 shows, the mean is quite comparable to the mean of current occupational status scores (45.9, SD 24.2) in this 
population; but it is substantially higher than the actual status scores of the first jobs held by DAS respondents (33.7, standard deviation 22.7, not shown in the table). Some emphasis can be given to the form in which the question was worded: It called for a hypothetical orientation that the respondent would have in beginning his work career, not for a report on what his motivational state actually was when he did commence working. It seems likely that occupational aspiration, measured in this way, will reflect the respondent's actual level of achievement to date as well as his initial motivation. This possibility is taken into account in our model, as noted subsequently.

The third indicator, social class identification, is based on responses to the following DAS questions:

Q. 76. There's quite a bit of talk these days about social class. If you were asked to use one of these four names for your social class, which would you say you belong in: middle class, lower class, working class, or upper class?

Q. 77. Would you say you are in the average part of the [class named in $Q .76]$ or in the upper part?

Numerical scores were assigned to responses as follows:

1. Lower class

2. Working class

3. Upper working class

4. Middle class

5. Upper middle class

6. Upper class

The sample mean was 2.45 and the standard deviation was 1.15 ; thus, both "working class" and "middle class" identifications were chosen by large numbers of respondents.

The first of these questions on class identification used in DAS (Q. 76) resembles the one proposed by the psychologist Richard Centers (1949). In Centers' work the responses are taken to indicate the "class consciousness" that emerges from the interplay of economic self-interest and the forces of economic circumstances encountered by the individual. Limitations of this point of view were suggested by Hodge and Treiman (1968), who pointed out that class identification correlates with the socioeconomic status of friends, neighbors, and relatives, independently of the respondent's own education, occupation, and income. We venture an interpretation of the question which differs considerably from those of previous investigators, to wit, that "class identification" is really, in part, a projective question that taps the respondent's desires or inclinations as well as (if not instead of) his estimate of his objective standing in society. With the DAS data we cannot, of course, put these alternative interpretations to any kind of rigorous test. But results obtained with our model seem consistent with the assumption that the 
response to this question, like those on work values and occupational aspiration, is an indicator of an unmeasured motivational factor which plays a role as an intervening variable in the process of achievement.

Some further notes on scoring procedures appear with Table 1 , which shows the means, standard deviations, and intercorrelations of the variables (including three unmeasured variables still to be described) considered in the study, other than the religion-ethnic classification. The mean scores on the measured variables for the 18 groups in that classification appear in Table 2. The last line of this table provides a descriptive statistic, the correlation ratio of each measured variable on the religion-ethnic classification, which reflects the degree to which these groups differ from each other. The classification, by itself, is seen to account for about $3 \%$ of the variation in the Protestant Ethic question $\left(y_{1}\right)$ but nearly $13 \%$ of the variation in father's occupation $\left(x_{7}\right)$, with the other variables falling between these extremes.

\section{THE MODEL}

While it is only moderately difficult to rationalize a model once it is formulated, it is often difficult to say where all the ideas came from that get translated into a model. The present model has evolved over a long period and undergone some major transformations. Featherman's first unpublished memorandum dates from December 1966. Further work resulted in the version presented by Duncan, Featherman, and Duncan (1968, section 7.6) and revised slightly for the Madison conference. Partly as a consequence of lessons derived from that conference and partly under the stimulation of Schuman's (1971) partial replication of Lenski's (1963) work, we enlarged the list of exogenous variables to include the religion-ethnic classification, took a different approach to the definition of unobserved variables, and improved our strategy of statistical estimation.

The model is presented in Fig. 1 in the form of a path diagram. Straight lines with arrows at one end represent coefficients measuring the dependence of endogenous variables upon other endogenous variables, exogenous variables, or disturbances. Curved lines represent correlations between exogenous variables (taken as given in the sample) or between disturbances, where not specified to be zero in the population. Unmeasured variables have letter subscripts and appear on the diagram in boxes to distinguish them from observed variables and disturbances. The $y$ 's are endogenous variables, the $u$ 's are disturbances, and the $x$ 's and $\left\{R_{j}\right\}$ are exogenous. The symbol $R_{j}(j=$ $1, \ldots, 18)$ represents a dummy variable for the $j^{\text {th }}$ religion-ethnic category. Hence, a dashed arrow leading from $\left\{R_{j}\right\}$ refers to a vector of structural coefficients and a dashed curve terminating at $\left\{R_{i}\right\}$ to a vector of correlations. We have, with minor modifications, followed Sewall Wright's (1934) 


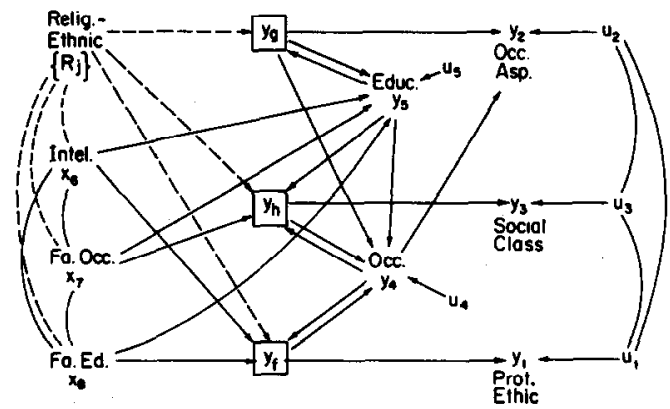

Fig. 1. Path diagram representing the model given by equations (1-8).

conventions for path diagrams, and we find the diagrammatic representation indispensable in thinking through the conceptual problems of model construction. However, we have not followed Wright's convention of expressing variables in standard form nor relied on path analysis algorithms in estimating coefficients.

The model consists of the following eight equations:

$$
\begin{aligned}
& y_{1}=y_{f}+u_{1} \\
& y_{2}=y_{g}+b_{24} y_{4}+u_{2} \\
& y_{3}=y_{h}+u_{3} \\
& y_{4}=b_{4 f} y_{f}+b_{4 g} y_{g}+b_{4 h} y_{h}+b_{45} y_{5}+u_{4} \\
& y_{5}=b_{5 g} y_{g}+b_{56} x_{6}+b_{57} x_{7}+b_{58} x_{8}+u_{5} \\
& y_{f}=b_{f 4} y_{4}+b_{f 6} x_{6}+b_{f 8} x_{8}+\Sigma_{j} b_{f i} R_{j}, j=1, \ldots, 18 \\
& y_{g}=b_{g 5} y_{5}+\Sigma_{j} b_{g j} R_{j}, j=1, \ldots, 18 \\
& y_{h}=b_{h 4} y_{4}+b_{h 5} y_{5}+b_{h 7} x_{7}+\Sigma_{j} b_{h j} R_{j}, j=1, \ldots, 18 .
\end{aligned}
$$

To avoid singularity, we constrain the coefficient of $R_{18}$ in each equation to be zero. All variables are expressed as deviations from their means. It will be noted that there are no disturbance terms in Eqs. (6-8) for the unmeasured factors, while those factors appear with unit coefficients in Eqs. (1-3) for their respective indicators.

In common with other models of the Blau-Duncan type, we take father's education and occupation as exogenous; and we treat our measure of intelligence in the same way. Similarly, we treat respondent's religious-ethnic classification as exogenous, despite the fact that it refers to current religious preference rather than preference at the outset of the occupational career or preference in the family of orientation. We know that some men change religious preference in the course of the life cycle and suspect that at least 
some of them do so to effect an adjustment to the degree of socioeconomic success or failure they have enjoyed (Warren, 1970). Here, as with the other exogenous variables, we forego any attempt to evaluate the effect of measurement errors, which, we suspect, may engender small, albeit not necessarily predictable, biases in our coefficient estimates.

Disturbances are specified to be uncorrelated with exogenous variables. Moreover, we treat $y_{5}$ as predetermined with respect to $y_{4}$ and both $y_{5}$ and $y_{4}$ as predetermined with respect to $y_{1}, y_{2}$, and $y_{3}$. Hence, $u_{4}$ and $u_{5}$ are uncorrelated with each other and with $u_{1}, u_{2}$, and $u_{3}$ although the latter are allowed to be correlated with each other. We are, therefore, retaining the basic recursive feature of the Blau-Duncan model, although simultaneity comes into the picture presently.

In our formulation, $y_{1}, y_{2}$, and $y_{3}$ are fallible indicators of the psychological dispositions that really influence achievement, $y_{f}, y_{g}$, and $y_{h}$. We reason that they are measured contemporaneously with the level of achievement that the dispositions presumably help to explain. For this reason, we do not assign any causal role to $y_{1}, y_{2}$, and $y_{3}$ themselves, but rather to their unobserved counterparts, $y_{f}, y_{g}$, and $y_{h}$. We are prepared to find rather high values of the disturbance variances in the first three equations.

If psychological dispositions are sociogenic as well as (or, perhaps, instead of) psychogenic, then we must reckon with the possibility that a disposition that is reflected in an indicator at a given time may have arisen in part as a consequence of the very activity that it tends to instigate. Thus, a man who has enjoyed economic security throughout his career may indeed find that his occupational decisions turn upon the degree to which the work gives a sense of accomplishment, whereas the man who has had to struggle for employment and a decent wage will understandably give priority to monetary return or job security. Hence, work values, as they develop in the course of the life cycle, may as well be caused by occupational achievement as be causes thereof. By the same token, although we presume that in reporting himself as "middle" or "upper" class a respondent is partially voicing an ambition or revealing a tendency to strive for status, we must acknowledge that his class identification may also be a consequence of the objective status attained. Similarly, the question designed to tap occupational aspiration cannot plausibly be assumed to be free of the effects of occupational level at the time of interview. Moreover, our impression is that the preferences for different kinds of work elicited by this question could well be modified as the individual attains successively higher levels of schooling, even though occupational ambition may be a significant spur to the pursuit of an education.

In short, we feel that the kinds of disposition reflected in the questions we are working with must realistically be conceived as interacting with the social roles incumbency of which they tend to encourage or discourage. Thus the model represents $y_{4}$ as being implicated in reciprocal causal relationships 
with both $y_{h}$ and $y_{f}$; and $y_{5}$ is involved with $y_{g}$ in the same way. Moreover, we allow a direct influence of occupation $\left(y_{4}\right)$ on the measured value of occupational aspiration $\left(y_{2}\right)$. Not only $y_{f}$ and $y_{h}$ but also $y_{g}$ appear in the set of influences on occupational achievement.

We have not, however, allowed $y_{f}$ and $y_{h}$ to serve as causes of educational attainment $\left(y_{5}\right)$. To do so would have broken down the recursive structure that we wished to carry over from earlier stratification models. This particular recursive feature seems to us rather basic in the general class of stratification models with which we are working. Moreover, it does not seem to have been challenged in any careful criticism of these models. The specification that the disturbances in the education and occupation equations are uncorrelated does, of course, put some strain on the assumption that we have identified and included all common causes of these two forms of achievement. In any given model this condition is not likely to be met literally. Yet most of the obvious "omitted variables" can be shown to be somewhat highly correlated with one or another of our exogenous variables and/or to have significant direct effects only upon education or upon occupation but not both. Hence, our specification is thought to incur relatively minor biases.

Although it appeared desirable to set up the model in such a way as to preclude indirect feedback from occupation to education, the particular arrangement of the three unmeasured variables that we propose to accomplish this is, admittedly, somewhat arbitrary. (One might argue that $y_{f}$ belongs where we have $y_{g}$ and vice vcrsa, for example.) The only test of our arrangement that we can think of consists of eyeballing the coefficient estimates for reasonableness. Perhaps an exceptionally energetic critic will wish to estimate a set of equations differently specified from ours in this important respect.

Particular attention is drawn to the main "engine" that "drives" this model: we have a priori excluded from the occupation $\left(y_{4}\right)$ and education $\left(y_{5}\right)$ equations the religion-ethnic variable. Some such exclusion is essential for identification. More important is the sense in which it expresses the particular theoretical bias we wish to impart to the model. We want to interpret all effects of religious-ethnic affiliation on achievement as working via the (unobserved) psychological dispositions, to put forward the best possible statistical case for the kind of argument made by Rosen (1959) and Lenski (1963). This strategy, obviously, does not result in a test of their kind of theory. We do not actually pit the cultural-psychological hypothesis against some alternative hypothesis and choose between them on the basis of a crucial statistic. We can in no sense prove the cultural-psychological argument. The nearest we could come to disproving it would be to show that the effects it posits do not appear, even when the model is biased in favor of bringing them to light. The reader must understand, therefore, that we are not proposing 
what we think of as a true model, but rather we are attempting to represent as well as possible with the data at hand one line of argument about the process of stratification-not necessarily the line that we ourselves find most plausible.

It is worth noting that the situation with this model is a particularly favorable one for our strategy in that we have as indicators of our unobserved dispositions not only some subjective questions which may be taken as psychological reflections of the dispositions, but also an antecedent variable, the religious-ethnic classification, which is taken to be an important source of the dispositions. Thus the dispositions are approached from both sides, and we are able to skirt completely the typical hazard of circular argument in motivational interpretations, i.e., that the motives may only be recognizable in the very behaviors that they are taken to explain.

\section{ESTIMATION AND RESULTS}

Since each of Eqs. (1-8) contains one or more unobserved variables, none of them can be estimated as it stands. We proceed to derive new equations by straightforward substitutions. Equations (6-8) respectively, are substituted into $(1-3)$ to obtain the following:

$$
\begin{aligned}
& y_{1}=b_{f 4} y_{4}+b_{f 6} x_{6}+b_{f 8} x_{8}+\Sigma_{j} b_{f j} R_{j}+u_{1} \\
& y_{2}=b_{24} y_{4}+b_{g 5} y_{5}+\Sigma_{j} b_{g j} R_{j}+u_{2} \\
& y_{3}=b_{h 4} y_{4}+b_{h 5} y_{5}+b_{h 7} x_{7}+\Sigma_{j} b_{h j} R_{j}+u_{3}
\end{aligned}
$$

where $j=1, \ldots, 18$, but the coefficients for $R_{18}$ are set at zero. Each of these equations contains only one endogenous variable, and so it may be estimated by ordinary least squares (OLS), and the same would be true of equations of the same form containing any or all of the exogenous variables.

Indeed, we first estimated versions of (1a-3a) containing all the predetermined variables. In the first version of (1a), the coefficient for $x_{7}$ had the wrong sign and a ratio of only -0.14 to its standard error; the coefficient for $y_{5}$ had a $t$-ratio of 1.41 . Both of these variables were dropped from the equation. Estimating the initial version of (2a) we obtained a coefficient for $x_{8}$ that had the wrong sign and a ratio of -.07 to its standard error; $x_{7}$ had a coefficient only 0.78 times as large as its standard error; and the coefficient for $x_{6}$ had a $t$-ratio of 1.17. All of these variables were dropped. In the initial version of (3a), we found that $x_{6}$ had a coefficient 0.63 times as large as its standard error, while $x_{7}$ and $x_{8}$ had coefficients respectively 1.23 and 1.35 times as large as the standard error. It was deemed advisable to retain onc of these in the model, and $x_{7}$ seemed conceptually more central. In the final version the estimated coefficient for this variable has a $t$-ratio of 1.91 . 
Although we relied heavily on significance tests with regard to the variables mentioned, in deciding to retain the religion-ethnic classification in each of these equations we were guided much more strongly by our conceptualization of the model. In view of the size of our sample, we are not surprised if a classification with 17 degrees of freedom does not always test out statistically significant. We do note that inclusion of the classification in each of the equations results in a substantively nontrivial increment to explained sums of squares. If we delete terms in $R_{j}$ from (1a-3a) and compute $R^{2}$ 's, we obtain the following (without) in comparison with the $R^{2}$ 's for those equations as written:

$\begin{array}{ccc} & \text { without } & \text { with }\left\{R_{j}\right\} \\ \text { (1a) } & .092 & .114 \\ \text { (2a) } & .151 & .168 \\ \text { (3a) } & .267 & .292\end{array}$

These results are taken to be consistent with the hypothesis that religious and ethnic factors give rise to differences in psychological dispositions.

The OLS estimates of coefficients in equations (1a-3a) appear in Table 3 , except that we have transformed the coefficients of the dummy variables to make them comparable to the deviations of variables $y_{1}, y_{2}$, and $y_{3}$ from the grand means in Table 2. It is of interest that these three equations produce distinct "profiles" of coefficients. No two of them include the same array of explanatory variables. Moreover, the religious-ethnic groups do not have the same patterns of coefficients on the three indicators. "Fundamentalists," for example, come out high on "Protestant Ethic" but low on social class. As noted earlier, however, it is probably best not to emphasize specific comparisons among these groups in view of the small numbers in most of them in our sample.

Proceeding to the occupation equation, we now solve (1), (2), and (3) respectively for $y_{f}, y_{g}$, and $y_{h}$, and substitute these solutions into (4). The result is

$$
y_{4}=a_{41} y_{1}+a_{42} y_{2}+a_{43} y_{3}+a_{45} y_{5}+v_{4}
$$

where

$$
\left.\begin{array}{l}
a_{41}=b_{4 f} /\left(1+b_{24} b_{4 g}\right) \\
a_{42}=b_{4 g} /\left(1+b_{24} b_{4 g}\right) \\
a_{43}=b_{4 h} /\left(1+b_{24} b_{4 g}\right) \\
a_{45}=b_{45} /\left(1+b_{24} b_{4 g}\right) \\
v_{4}=\left(u_{4}-b_{4 f} u_{1}-b_{4 g} u_{2}-b_{4 h} u_{3}\right) /\left(1+b_{24} b_{4 g}\right)
\end{array}\right\}
$$


TABLE 3

OLS Estimates of Coefficients in Equations (1a-3a) $a$

\begin{tabular}{|c|c|c|c|}
\hline Independent variable & $\begin{array}{c}\text { Eq. (1a), } \\
\text { Prot. Ethic }\left(y_{1}\right)\end{array}$ & $\begin{array}{c}\text { Eq. (2a) } \\
\text { Occ. asp. }\left(y_{2}\right)\end{array}$ & $\begin{array}{c}\text { Eq. (3a) } \\
\text { Soc. class }\left(y_{3}\right)\end{array}$ \\
\hline$y_{4}$ (Occupation) & $\begin{array}{c}.0028 \\
(.0006)\end{array}$ & $\begin{array}{c}.132 \\
(.031)\end{array}$ & $\begin{array}{l}.014 \\
(.002)\end{array}$ \\
\hline$y_{s}$ (Education) & $\begin{array}{l}- \\
-\end{array}$ & $\begin{array}{l}3.11 \\
0.48\end{array}$ & $\begin{array}{l}.168 \\
(.027)\end{array}$ \\
\hline$x_{6}$ (Intelligence) & $\begin{array}{c}.0099 \\
(.0027)\end{array}$ & $\begin{array}{l}- \\
-\end{array}$ & $\begin{array}{l}- \\
-\end{array}$ \\
\hline$x_{7}$ (Father's occ.) & $\begin{array}{l}- \\
-\end{array}$ & $\begin{array}{l}- \\
-\end{array}$ & $\begin{array}{l}.0030 \\
(.0016)\end{array}$ \\
\hline$x_{8}$ (Father's educ.) & $\begin{array}{l}.023 \\
(.008)\end{array}$ & $\begin{array}{l}- \\
-\end{array}$ & $\begin{array}{l}- \\
-\end{array}$ \\
\hline \multicolumn{4}{|l|}{ Religion-Ethnic, $j=$} \\
\hline 1 Jewish & -.055 & 2.8 & .43 \\
\hline 2 Irish Cath. & -.081 & -1.9 & .07 \\
\hline 3 Ger. Cath. & .029 & 0.2 & -.25 \\
\hline 4. French Cath. & -.059 & -3.1 & -.20 \\
\hline 5 Polish Cath. & .007 & -1.3 & -.04 \\
\hline $\begin{array}{l}6 \text { Ital. Cath. } \\
7 \text { Cath., other N.W. }\end{array}$ & -.117 & 2.8 & -.13 \\
\hline Eur. and N. Amer. & .052 & 1.9 & .09 \\
\hline 8 Other Cath., Orth. & .010 & 0.7 & -.11 \\
\hline 9 Ger. Lutheran & .039 & 0.3 & .06 \\
\hline 10 Other Luth. & -.016 & -4.4 & .26 \\
\hline 11 Presbyterian & .048 & -1.2 & -.08 \\
\hline 12 Episcopalian & -.004 & -1.0 & .40 \\
\hline 13 Methodist & .091 & 1.3 & .10 \\
\hline 14 Baptist & -.033 & 3.8 & -.14 \\
\hline 15 Prot., nondenom. & -.068 & -3.5 & .07 \\
\hline 16 "Fundamentalist" & .164 & -1.8 & -.35 \\
\hline 17 No religion & -.065 & -0.9 & .18 \\
\hline 18 Residual & -.003 & 6.7 & .34 \\
\hline$R^{2}$ & .114 & .168 & .292 \\
\hline
\end{tabular}

aNote: Figures in parentheses are standard errors. For comparison with Table 2, the coefficients for dummy variables have been transformed so that their weighted mean, using $n_{j}$ from Table 2 as the weight, is zero.

We see that three of the right-hand variables in (4a) are correlated with the disturbance, so that OLS is not a consistent method of estimation. But we have $y_{5}$ and the 20 exogenous variables as predetermined variables, so that the equation is overidentified. We proceed, therefore, to estimate (4a) by twostage least squares (2SLS) with $y_{5}, x_{6}, x_{7}, x_{8}$, and $R_{1}, \ldots, R_{17}$ as predetermined variables. 
Actually, the specification of (4a) and (4) was arrived at only after trying various alternative versions of (4a). The results of estimating these by 2SLS are reported in Table 4. Equation (4a) itself is not entirely satisfactory, since the coefficient for neither $y_{f}$ nor $y_{g}$ is as large as two standard errors. Equation (4b), dropping education $\left(y_{5}\right)$, remedies this situation for $y_{g}$ though not for $y_{f}$. Nevertheless, Eq. (4b) seems highly questionable, both conceptually and statistically. The remaining versions, $(4 c-4 f)$, were run to investigate the advisability of including one or another of the exogenous variables in the occupation equation. On the basis of the standard errors as well as the numerical magnitudes of the coefficients, there is little reason to include father's education $\left(x_{8}\right)$ or father's occupation $\left(x_{7}\right)$. The latter result is of some conceptual interest, for it is usual in Blau-Duncan models to find that father's occupation has a small but significant path even when respondent's education and various exogenous variables are in the equation (see the $y_{4}$ equation in Table 5). The finding that it may be dropped from Eq. (4) can be interpreted as an indication that the psychological variables adequately pick up what had hitherto looked like a direct effect of father's occupation.

Version (4e) is more perplexing. When intelligence $\left(x_{6}\right)$ is in the equation, it turns up with a coefficient that has a $t$-ratio of 1.57 ; at the same time the coefficient for $y_{f}$ (the unobserved variable corresponding to the

TABLE 4

2SLS Estimates of Coefficients in Various Versions of Equation (4a)

\begin{tabular}{lcccccc}
\hline & \multicolumn{6}{c}{ Alternative version of Equation (4a) } \\
\cline { 2 - 7 } Independent variable & $(4 \mathrm{a})$ & $(4 \mathrm{~b})$ & $(4 \mathrm{c})$ & $(4 \mathrm{~d})$ & $(4 \mathrm{e})$ & $(4 \mathrm{f})$ \\
\hline$y_{1}$ & 10.7 & 12.2 & 9.91 & 8.51 & 3.64 & - \\
& $(8.9)$ & $(10.8)$ & $(8.65)$ & $(9.89)$ & $(9.68)$ & - \\
$y_{2}$ & 0.450 & 0.815 & 0.417 & 0.460 & 0.367 & 0.374 \\
& $(0.256)$ & $(0.246)$ & $(0.250)$ & $(0.254)$ & $(0.251)$ & $(0.252)$ \\
$y_{3}$ & 10.9 & 14.0 & 9.5 & 10.3 & 10.3 & 10.5 \\
& $(3.0$ & $(3.2)$ & $(3.2)$ & $(3.2)$ & $(2.9)$ & $(2.9)$ \\
$y_{5}$ (Educ.) & 3.03 & - & 3.51 & 3.21 & 3.45 & 3.53 \\
& $(1.30)$ & - & $(1.35)$ & $(1.33)$ & $(1.27)$ & $(1.26)$ \\
$x_{6}$ (Intel.) & - & - & - & - & 0.296 & 0.329 \\
& - & - & - & - & $(0.189)$ & $(0.168)$ \\
$x_{7}$ (Father's occ.) & - & - & 0.035 & - & - & - \\
& - & - & $(0.036)$ & - & - & - \\
$x_{8}$ (Father's Educ.) & - & - & - & 0.254 & - & - \\
& - & - & - & $(0.509)$ & - & - \\
$R^{2}$ & .260 & -.086 & .311 & .278 & .321 & .312 \\
\hline
\end{tabular}

Note: Figures in parentheses are estimated standard errors. $R^{2}$ is defined as 1 $\operatorname{Var}\left(\hat{v}_{4}\right) / \operatorname{Var}\left(y_{4}\right)$. 
TABLE 5

Regression Coefficients in Semi-Reduced Form of the Occupation Equation and Reduced Form of the Education Equation, as Derived from Estimated Structural Coefficients and as Directly Estimated by OLS ${ }^{a}$

\begin{tabular}{|c|c|c|c|c|}
\hline \multirow[b]{2}{*}{ Independent variable } & \multicolumn{2}{|c|}{ Occupation $\left(y_{4}\right)$} & \multicolumn{2}{|c|}{ Education $\left(y_{5}\right)$} \\
\hline & Derived & OLS & Derived & OLS \\
\hline$y_{5}$ (Education) & 8.22 & $7.32^{c}$ & - & - \\
\hline$x_{6}$ (Intelligence) & .139 & $.460^{c}$ & .143 & $.141^{c}$ \\
\hline$x_{7}$ (Father's occ.) & .043 & $.065^{c}$ & .0080 & $.0069 c$ \\
\hline $\begin{array}{l}x_{8} \text { (Father's educ.) } \\
\text { Religion-Ethnic, } j=\end{array}$ & .324 & $.765^{b}$ & .132 & $.130^{c}$ \\
\hline 1 Jewish & 7.1 & 4.2 & .12 & .98 \\
\hline 2 Irish Cath. & -1.2 & 0.9 & -.08 & .03 \\
\hline 3 Ger. Cath. & -3.0 & -0.4 & .01 & .00 \\
\hline 4 French Cath. & -5.4 & -3.0 & -.13 & -.01 \\
\hline 5 Polish Cath. & -1.3 & -2.0 & -.06 & -.03 \\
\hline 6 Ital. Cath. & -1.9 & 1.5 & .12 & .19 \\
\hline \multicolumn{4}{|l|}{7 Cath., other N.W. Eur. } & -.38 \\
\hline 8 Other Cath., Orth. & -0.9 & 1.2 & .03 & .17 \\
\hline 9 Ger. Lutheran & 1.6 & 3.4 & .01 & .13 \\
\hline 10 Other Luth. & 0.9 & -5.4 & -.19 & -.08 \\
\hline 11 Presbyterian & -1.1 & 2.5 & -.05 & .35 \\
\hline 12 Episcopalian & 5.1 & 1.9 & -.04 & -.04 \\
\hline 13 Methodist & 3.6 & -0.2 & .06 & -.11 \\
\hline 14 Baptist & -0.2 & -2.2 & .16 & -.26 \\
\hline 15 Prot., nondenom. & -2.0 & 4.9 & -.15 & -.63 \\
\hline 16 "Fundamentalist" & -3.8 & -8.1 & -.08 & -.23 \\
\hline 17 No religion & 1.1 & 4.8 & -.04 & -.09 \\
\hline 18 Residual & 8.8 & 4.3 & .29 & .39 \\
\hline$R^{2}$ & .373 & .399 & .374 & .402 \\
\hline \multicolumn{5}{|l|}{$R^{2}$ for equation omitting } \\
\hline religion-ethnic dummies & - & .384 & - & .374 \\
\hline
\end{tabular}

$a_{\text {Note: }}$ For comparison with Table 2 , the coefficients for dummy variables have been transformed so that their weighted mean, using $n_{j}$ from Table 2 as the weight, is zero.

$b_{\text {Ratio to }} \mathrm{SE}$ is between 1.0 and 2.0 .

$c$ Ratio to SE exceeds 2.0 .

Protestant Ethic) drops to a negligible size. One could argue that what we have in $y_{f}$ is a rather clumsy proxy for intelligence, rather than a variable that is distinctively motivational in nature. At any rate, there is presented for the analyst's consideration a kind of tradeoff: if he wants to argue for a direct effect of intelligence on occupational achievement (in addition to its indirect effect via education), he must give up any emphasis on a Protestant Ethic sort of motivational variable; but if the motivational variable is retained, the effect 
of intelligence is in doubt. To be consistent with our strategy of emphasizing the motivational variables where the situation is ambiguous, we have adopted the latter resolution of the dilemma. In opting for Eq. (4a), therefore, we discard the intelligence variable whose significance is on the borderline but retain the two motivation variables, $y_{f}$ and $y_{g}$, whose significance is at least equally questionable. For the benefit of readers who may prefer the alternative resolution of the dilemma, we provide estimates for version (4f), which eliminates $y_{f}$ from the equation but retains $x_{6}$. In that event, the $t$-ratio for $\hat{a}_{46}$ rises to 1.96 . We are not, therefore, taking issue with an argument placing greater stress on intelligence but simply reiterate that the rhetorical strategy of this paper was to give the benefit of any doubt to the motivational variables.

Having decided to adopt (4a), we obtain estimates of the coefficients in (4) by solving for the $b$ 's in (9). That is, we take the $\hat{a}$ 's estimated for equation (4a) and $b_{24}$ as estimated for Eq. (2a) and compute the remaining $\hat{b}$ 's from the following formulas:

$$
\begin{array}{ll}
\hat{b}_{4 g}=\hat{a}_{42} /\left(1-\hat{a}_{42} \hat{b}_{24}\right) \\
\hat{b}_{4 f}=\hat{a}_{41}\left(1+\hat{b}_{24} \hat{b}_{4 g}\right) \\
\hat{b}_{4 h}=\hat{a}_{43} \quad\left(1+\hat{b}_{24} \hat{b}_{4 g}\right) \\
\hat{b}_{45}=\hat{a}_{45} \quad\left(1+\hat{b}_{24} \hat{b}_{4 g}\right) .
\end{array}
$$

With $\hat{b}_{24}=0.132$, the $\hat{b}$ 's do not differ greatly from the corresponding $\hat{a}$ 's. We obtain the following estimate for Eq. (4):

$$
y_{4}=11.4 y_{f}+0.478 y_{g}+11.6 y_{h}+3.23 y_{5}+\hat{u}_{4}\left(R^{2}=.588\right) \text {. }
$$

Proceeding to the education equation, we substitute the expression for $y_{g}$ obtained from Eq. (2) into Eq. (5) and obtain

$$
y_{5}=b_{5 g}\left(y_{2}-b_{24} y_{4}\right)+b_{56} x_{6}+b_{57} x_{7}+b_{58} x_{8}+v_{5}
$$

where

$$
v_{5}=u_{5}-b_{5} u_{2} \text {. }
$$

A full information approach would use (2a) and (5a) jointly to estimate all parameters. We adopt a simpler expedient, in the spirit of 2SLS, to handle the problem posed by the first term on the right. We substitute $\hat{b}_{24}$ (previously obtained) for $b_{24}$, create a new variable, $y_{2}-\hat{b}_{24} y_{4}$, and proceed with 2SLS estimation of parameters in (5a), using the exogenous variables as instruments. We obtain the following estimates for equation (5), with the standard errors in parentheses:

$$
\begin{aligned}
y_{5}= & 0.0384 y_{g}+0.126 x_{6}+0.00702 x_{7}+0.116 x_{8}+\hat{u}_{5} \\
(0.016) & (0.012) \quad(0.0022)
\end{aligned}
$$


All the coefficients are clearly significant, so that we are not tempted to consider any alternative specification of this equation. The significance of coefficients for $x_{7}$ and $x_{8}$ is of some substantive interest for anyone who believes that ostensible direct effects of these variables in a Blau-Duncan model primarily represent the impact of family socialization on the formation of status ambitions. If our model is correct, something more than thisperhaps mere economic strength-seems to be at stake.

It may be noted in passing that although we specify that the disturbances in (4) and (5) are uncorrelated, this does not carry over to (4a) and (5a). In fact, the correlation of sample residuals, $\hat{v}_{4}$ and $\hat{v}_{5}$, is 21 .

In evaluating the model, it is helpful to examine the results obtained when the unmeasured variables are omitted. In Table 5 we present estimates for the two main equations of the model with the motivational variables solved out. The "derived" estimates work backward from the structural equations, substituting Eq. (6-8) into Eqs. (4-5); this yields

$$
y_{4}=b_{45}^{\prime} y_{5}+b_{46}^{\prime} x_{6}+\mathrm{b}_{47}^{\prime} x_{7}+b_{48}^{\prime} x_{8}+\Sigma_{j} b_{4 j}^{\prime} R_{j}+u_{4}^{\prime} \text {, }
$$

where

$$
\begin{aligned}
& b_{45}^{\prime}=\left(b_{45}+b_{4 g} b_{g 5}+b_{4 h} b_{h 5}\right) / K \\
& b_{46}^{\prime}=b_{4 f} b_{f 6} / K \\
& b_{47}^{\prime}=b_{4 h} b_{h 7} / K \\
& b_{48}^{\prime_{4}}=b_{4 f} b_{f 8} / K \\
& b_{4 j}^{\prime}=\left(b_{4 f} b_{f j}+b_{4 g} b_{g j}+b_{4 h} b_{h j}\right) / K \\
& u_{4}^{\prime}=u_{4} / K \\
& K=1-b_{4 f} b_{f 4}-b_{4 h} b_{h 4}
\end{aligned}
$$

and

$$
y_{5}=b^{\prime}{ }_{56} x_{6}+b^{\prime}{ }_{57} x_{7}+b^{\prime}{ }_{58} x_{8}+\Sigma_{j} b^{\prime}{ }_{5 j} R_{j}+u^{\prime}{ }_{5},
$$

where

$$
\begin{aligned}
& b_{56}^{\prime}=b_{56} / L \\
& b^{\prime}{ }_{57}=b_{57} / L \\
& b_{58}^{\prime}=b_{58} / L \\
& b^{\prime}{ }_{5 j}=b_{5 g} b_{g j} / L \\
& u_{5}^{\prime}=u_{5} / L
\end{aligned}
$$

and

$$
L=1-b_{5 g} b_{85} .
$$

"Derived" estimates of the $b^{\prime}$ coefficients are computed by inserting into each of these formulas the estimate $\hat{b}$ corresponding to the structural coefficient $b$. OLS estimates are obtained by OLS applied directly to Eq. $\left(4^{\prime}\right.$ and $\left.5^{\prime}\right)$. 
In the case of the education equation, $\left(5^{\prime}\right)$, the OLS and derived coefficients agree fairly closely as far as $x_{6}, x_{7}$, and $x_{8}$ are concerned. The two sets of coefficients for the religion-ethnic groups are, however, only broadly similar. The reason for the differences is clear. The OLS estimates are obtained by regressing education itself on religion-ethnic categories (along with the other exogenous variables), whereas the derived coefficient for the $j$ th religious-ethnic group is obtained from the calculation,

$$
\hat{b}_{5 g} \hat{b}_{g j} /\left(1-\hat{b}_{5 g} \hat{b}_{g 5}\right)=.0435 \hat{b}_{g j} \text {. }
$$

Hence, roughly speaking, the derived education coefficients for the religionethnic groups are merely transformations of the group differences in occupational aspiration $\left(y_{2}\right)$, which is our indicator of $y_{g}$. Thus, a close correlation between the derived coefficients for education in Table 5 and the mean scores on $y_{2}$ in Table 2 is evident. The discrepancies between the two sets of education coefficients in Table 5 , therefore, essentially reflect the imperfect between-group correlation of occupational aspiration and educational attainment, inasmuch as our model allows religious-ethnic classification to affect education only via $y_{\boldsymbol{g}}$. It is possible that the fit of derived to OLS coefficients would be improved if we were to allow some religion-ethnic groups to have direct effects on education; but the specification of which ones to treat in this fashion would be quite arbitrary from a substantive viewpoint.

In the case of the occupation equation, $\left(4^{\prime}\right)$, the OLS and derived estimates are fairly different for all coefficients. If the model is correct, presumably the latter are preferred estimates. However, it is somewhat disconcerting that the coefficient for $y_{5}$ (education) is substantially larger while the coefficients for $x_{6}, x_{7}$, and $x_{8}$ are smaller in the derived set than in the OLS set. Discrepancies like these suggest the desirability of performing a statistical test of the overidentifying restrictions of the model. However, we have not attempted to carry out such a test. Clearly, some question remains about the specification of this equation, in view of this result and the equivocal outcome of significance tests on the structural coefficients.

In any event, the "Protestant Ethic" thesis certainly receives no strong support-recall the low $t$-ratio for $y_{1}$ in equation (4a) and the debatable outcome of the comparison between (4a) and (4e). On the other hand, one of the major consequences of including the other two psychological variables is to reduce sharply the estimated direct effect of educational attainment on occupational achievement. Whereas that effect is estimated at 7.3 in Table 5 by OLS in a model excluding psychological variables, it drops to 3.0 in Eq. (4a) [or 3.5 in Eqs. (4c and 4f)] in Table 4. Now, it may well be that education influences occupation primarily by giving rise to motives that instigate occupational ambition and performance; but in most discussions this causal path has not received an emphasis commensurate with these estimates. We must point out, therefore, that the argument for motives as key factors in 
achievement seems to entail a correlative deemphasis of the cognitive and instrumental functions of education for allocation to occupational roles.

Readers acquainted with psychometric techniques may wonder why we have allowed unobserved factors to proliferate in our model to the extent of having three of them corresponding to an equal number of indicators. Would it not have made more sense to posit a single common factor (or two at most), estimate the factor loadings, and use these results to devise a composite motivational variable for inclusion in the model? Some of the issues raised by such a procedure are discussed in Hauser's paper at the conference. For our part, we wanted to entertain a somewhat more complicated hypothesis than is expressed by the conventional factor models. In particular, we thought it necessary to allow at least one of our indicators to be directly "contaminated" by another measured variable in the model.

Similarities and differences between our procedure and the usual psychometric one are suggested by the path diagrams in Figure 2. The upper one extracts Eqs. (1-3) from the model and treats them as a self-contained block in which the predetermined variables $\left(y_{f}, y_{g}, y_{h}\right)$ are merely intercorrelated, without regard to the causal structure producing those correlations. The lower diagram represents the model of a single common factor, symbolized by a "grey box." Standardized path coefficients are posted on the straight lines with arrows at one end; and correlations are posted on the curved lines with arrows at both ends, following Wright's (1934) convention. In the lower diagram, the path coefficients for arrows leading from the grey box are factor loadings; if one squares the values of the residual paths, one obtains the respective unique variances of the indicators. With only three indicators, of course, the common factor solution is trivial; barring the "Heywood case," it is guaranteed completely to account for the intercorrelations of the indicators. In our model, such correlations are accounted for, not by a single (unob-
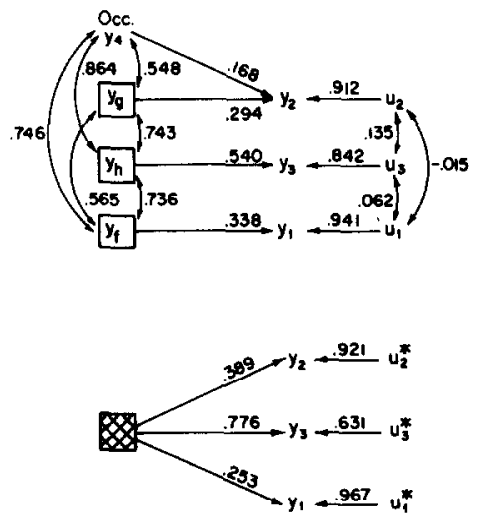

Fig. 2. (Above) Correlations among social-psychological indicators accounted for by the model in this paper and (below) by a single common factor. 
served) common factor, but by a set of (observed and unobserved) causes, which are themselves intercorrelated. But there is no constraint in our mo requiring that it fully account for the correlations among the indicators. Thus, it is of substantive interest that the residuals for $y_{1}$ and $y_{2}$ correlate virtually nil while both have slight positive correlations with the residual for $y_{3}$. It seems that there is some modest amount of nonunique variance in the social class item that we are not taking into account in the model. Nevertheless, social class has the smallest residual variance of the three indicators in our model just as it has the least uniqueness in the factor analysis model. In both diagrams, actually, all the indicators have a great deal of variance not accounted for.

In the upper diagram one can read off the correlation between the indicators and the corresponding unobserved factors. Thus $r_{1 f}=p_{1 f}=.338$ and $r_{3 h}=p_{3 h}=.540$. But since $y_{2}$ is determined not only by an unmeasured factor but also by $y_{4}$ we have $r_{2 g}=p_{2 g}+p_{24} r_{4 g}=.294+.092=.386$. All these correlations point to the rather low level of validity of the indicators. If our model is correct, however, our estimates of the structural coefficients for the unmeasured factors are not hiased by this low validity. On the other hand, if the critic insists that we have substantially underestimated the validity of the indicators he will have to concede that we have somehow specified the model in such a way as to exaggerate the correlation of the unmeasured factors with occupation. Given $r_{14}$ (for example), if we raise $p_{1 f}$ we must lower $r_{4 f}$.

It does not appear that we could have greatly improved our results from this critic's point of view by using a factor-weighted or other composite of our three indicators. Such a variable, it is clear from the lower diagram, would be dominated by the one indicator, social class identification. But we already have a pretty good idea of how this variable works in the context of our kind of model. In any event, we do not feel uncomfortable with the notion that $y_{f}$, $y_{g}$, and $y_{h}$ comprise a dispositional "syndrome" without being merely different measures of the "same thing." Indeed, we suspect that in a context where a multiplicity of motivational indicators is available, one will find that these three will have their highest loadings on different factors.

We do not suggest that the foregoing observations dispose of the problem of validity. It may be that indicators quite different in content from those we had available are required to come to grips with the issues posed by the psychological theories of achievement. It may be, too, that some relevant social psychological factors are not only different in content from those we tapped but are also uncorrelated with intelligence, socioeconomic background, and religion-ethnic affiliation. In that event their effects are captured only in the disturbance terms of our equations. 


\section{ACKNOWLEDGMENTS}

We are grateful to Professors Edward O. Laumann and Howard Schuman, Directors of the 1966 Detroit Area Study, for permission to use data collected in that project. A preliminary version of this paper appeared in the report by Duncan, Featherman, and Duncan (1968, section 7.6) submitted to the U.S. Office of Education. Additional work was completed in connection with NSF project GS 2707, "Causal Models in Social Research." J. Michael Coble prepared the programs used in computation; and Eugene Won assisted with the calculations. The paper was presented to the Conference on Structural Equation Models, sponsored by the Social Science Research Council and held in Madison, Wisconsin, November 12-16, 1970. Suggestions of the conference chairman, Arthur S. Goldberger, were invaluable.

\section{REFERENCES}

Allport, F. H. (1934), The J-curve hypothesis of conforming behavior, Journal of Social Psychology 5, 141-183.

Blau, P. M., and Duncan, O. D. (1967), "The American Occupational Structure," Wiley, New York.

Centers, R. (1949), "The Psychology of Social Classes," Princeton University Press, Princeton.

Crockett, H. J., Jr. (1966), Psychological origins of mobility, in "Social Structure and Mobility in Economic Development," (N. J. Smelser and S. M. Lipset, Eds.), Aldine Pub. Co., Chicago.

Duncan, B., and Duncan, O. D. (1968), Minorities and the process of stratification, American Sociological Review 33, 356-364.

Duncan, O. D. (1968), Ability and achievement, Eugenics Quarterly 15, 1-11.

Duncan, O. D. (1969), Contingencies in constructing causal models, in "Sociological Methodology 1969," (E. F. Borgatta, Ed.), Jossey-Bass Inc., San Francisco.

Duncan, O. D., Featherman, D. L., and Duncan, B. (1968), "Socioeconomic Background and Occupational Achievement: Extensions of a Basic Model," University of Michigan, Ann Arbor. Final Report, Project No. 5-0074 (EO-191), Contract No. OE-5-85-072, U.S. Office of Education.

Featherman, D. L. (1971), The socioeconomic achievement of white religio-ethnic subgroups: social and psychological explanations, American Sociological Review 36, 207-222.

Gockel, G. (1969), Income and religious affiliation: a regression analysis, American Journal of Sociology 74, 632-649.

Goldstein, S. (1969), Socioeconomic differentials among religious groups in the United States, American Journal of Sociology 74, 612-631.

Hodge, R. W., and Treiman, D. J. (1968), Class identification in the United States, American Journal of Sociology 75, 535-547.

Kahl, J. A. (1965), Some measurements of achievement motivation, American Journal of Sociology 70, 669-681.

Lenski, G. (1963) [1961], "The Religious Factor," Anchor Books, Doubleday, Garden City, NY.

Morgan, J. N., and others (1962), "Income and Welfare in the United States," McGraw-Hill, New York.

Reiss, A. J., Jr., and others (1961), "Occupations and Social Status," Free Press of Glencoe, New York. 
Rosen, B. C. (1959), Race, ethnicity, and the achievement syndrome, American Sociological Review 24, 47-60.

Schuessler, K. (1971), "Analyzing Social Data," Houghton Mifflin Co., Boston.

Schuman, H. (1971), The religious factor in Detroit: review, replication, and reanalysis, American Sociological Review 36, 30-48.

Sewell, W. H., and Shah, V. P. (1967), Socioeconomic status, intelligence, and the attainment of higher education, Sociology of Education 40, 1-23.

Stacey, B. G. (1965), Some psychological aspects of intergeneration occupational mobility, British Journal of Social and Clinical Psychology 4, 275-286.

Warren, B. L. (1970), Socioeconomic achievement and religion: the American case, Sociological Inquiry 40, 130-155.

Wechsler, D. (1955), "Manual for the Wechsler Adult Intelligence Scale," Psychological Corp., New York.

Wright, S. (1934), The method of path coefficients, Annals of Mathematical Statistics 5, 161-215. 